\title{
Del turismo escolar y sanitario infantil al turismo social: colonias de vacaciones en la Provincia de Buenos Aires, Argentina
}

\section{From educational and health tourism for children to social tourism: vacation camps in the Province of Buenos Aires, Argentina}

\section{Perla Bruno}

Profesora, Facultad de Arquitectura, Urbanismo y Diseño/ Universidad Nacional de Mar del Plata; directora, Registros: Revista de Investigación Histórica.

Complejo Manuel Belgrano, Funes 3.350, $3^{\circ}$ piso.

B7602AYL - Mar del Plata Argentina

pbruno@mdp.edu.ar
BRUNO, Perla. Del turismo escolar y sanitario infantil al turismo social: colonias de vacaciones en la Provincia de Buenos Aires, Argentina. História, Ciências, Saúde-Manguinhos, Rio de Janeiro, v.24, n.4, out.-dez. 2015, p.1467-1490.

Resumen

A principios del siglo XX se originan las colonias de vacaciones para niños débiles como experiencias educativas y sanitarias realizados por organizaciones médicas y filantrópicas. El análisis de estas experiencias en la Provincia de Buenos Aires, concebidas aquí como antecedentes del turismo social, constituye el objetivo del trabajo. Se combinan fuentes escritas, fundamentalmente memorias institucionales, publicaciones periódicas, como el Monitor de la Educación Común - órgano del Consejo Nacional de Educación - o leyes, con fotos y planos de los distintos ejemplos. Se considera, finalmente, que estos edificios son "marcas", tanto físicas como culturales en los lugares donde se localizan, con expresiones arquitectónicas que condensan las ideas sobre el espacio del ocio y la cura en entornos naturales singulares.

Palabras clave: historia del turismo; colonias de vacaciones; niños débiles; turismo social.

\section{Abstract}

The early twentieth century saw the rise of vacation camps for frail children as educational and health-giving experiences provided by medical and philanthropic organizations. This article analyzes some of these early experiences, seen here as the predecessors of social tourism, in the Province of Buenos Aires. A combination of written sources are examined, mainly institutional reports, periodicals such as the Monitor de la Educación Común - published by the Consejo Nacional de Educación (National Board of Education) - or laws, with photographs and plans for different examples. I argue that these buildings were both physical and cultural "brands" in the places where they were located, and that their architectural structure encapsulated ideas about leisure space and cures in unique natural environments.

Keywords: history of tourism; vacation camps; frail children; social tourism. 
$\mathrm{C}$ omo es sabido, las primeras experiencias turísticas en la Argentina se inician en el siglo XIX con el termalismo, los balnearios de río y posteriormente con los balnearios de mar. En estos centros se realizan los grandes hoteles, en marcos naturales imponentes, y con multiplicidad de espacios que hacían posible las actividades de ocio de la sociedad decimonónica. El final del siglo fue testigo también de transformaciones urbanas en las ciudades más importantes del país, donde se construyen los nuevos hoteles urbanos, con sus arquitecturas públicas, como las del Palace o el Plaza Hotel en Buenos Aires.

En las primeras décadas del siglo XX, mientras esta hotelería de lujo llega a su máximo esplendor, se originan, específicamente vinculados a la salud fundamentalmente infantil, las colonias de vacaciones para niños débiles, como experiencias educativas y sanitarias realizados por organizaciones médicas, educativas, o filantrópicas, en entornos naturales y aislados de las malas condiciones en las que se suponía que se vivía en las grandes ciudades. Precisamente, el análisis de algunas de estas primeras experiencias sanitario-educativas y de los edificios construidos para satisfacer esta nueva demanda en el territorio provincial constituye el objetivo del trabajo.

De lo expuesto se desprende que el estudio registra antecedentes diversos, comenzando por la historia del turismo. A nivel internacional, Pousada (2002) plantea tres condiciones para que el turismo - traslados temporales en búsqueda de satisfacción - se transforme de deseo en realidad: disposición de renta y tiempo libre, medios de transportes y agentes que faciliten la recepción y estancia. Sujetos y motivos del viaje cambian históricamente. Así, Boyer (2002) sugiere buscar las causas del turismo europeo - entendido como una adquisición cultural - en un proceso de invenciones que crean prácticas, comportamientos y lugares, seguidos de una difusión por imitación. A nivel nacional destacan las contribuciones de Pastoriza (2011) a la historia del turismo argentino, o a las políticas públicas sobre turismo en la gobernación mercante (Pastoriza, 2005). También debe apuntarse la tesis de Piglia (2014), la cual analiza la configuración del turismo como problema público.

Otras contribuciones a la construcción de la problemática provienen de la historia de la educación (Lionetti, 2009). Desde la historia de la salud (Herrero, Carbonetti, 2013), y focalizados en la Provincia de Buenos Aires deben mencionarse los trabajos de Adriana Álvarez (2010; Álvarez, Reynoso, 1995).

Desde la historia de la arquitectura, varios trabajos centran la atención en la arquitectura hotelera, no habiendo sido consideradas aún estas colonias de vacaciones como programa específico. Cunha Matos (2007) estudia los hoteles de Portugal con quien compartimos la consideración de que dichos edificios son "marcas" en el territorio. Referido específicamente al hotel de turismo en España, Jiménez Morales (2013), estima que los mismos constituyen "piezas mínimas" en tanto son necesarios para convertir un lugar en destino turístico. Citemos finalmente algunas investigaciones nuestras (Mazza, Bruno, 2009; Bruno, 2012).

Reconociendo estos aportes, el trabajo analiza las primeras experiencias de colonias de vacaciones y sus edificios a partir de dos supuestos básicos. Desde el punto de vista social, estas experiencias con niños - su traslado en épocas estivales a medios naturales, lejos las ciudades, en condiciones de alojamiento higiénico y adecuado - introducen prácticas que en alguna medida se continúan en el turismo social. Desde lo arquitectónico, se generaron una serie de edificios que perduran como "marcas", tanto físicas como culturales, en el territorio 
provincial, con expresiones arquitectónicas particularizadas que condensan las ideas sobre el espacio del ocio y la cura en entornos naturales singulares.

Por último, la exposición se organiza en tres partes derivadas de advertir tres momentos distintos en las realizaciones de las colonias en el territorio provincial. El primero se corresponde con las colonias de vacaciones realizadas, en el país, en las dos primeras décadas del siglo XX, y que respondían a necesidades sanitarias - fundamentalmente la lucha antituberculosa - tomando como ejemplo la Colonia de Niños débiles de Necochea. Un segundo momento tiene lugar desde mediados de los años 1930, en el que coinciden la obra de las colonias provinciales del gobernador Manuel Fresco (1936-1940), cuyas realizaciones se orientan fundamentalmente a las actividades de fortalecimiento del cuerpo de jóvenes y niños mediante la ejercitación física y vida al aire libre, con una nueva etapa de las colonias del Consejo Nacional de Educación, con edificios diseñados para ese fin. De esos se considerará la Colonia Marítima de Mar del Plata. El último momento corresponde al gobierno de Domingo Mercante (1946-1952) cuando la obra pública destinada al turismo es parte de la política de fomento del turismo social. El ejemplo a considerar es la colonia de Monte Hermoso.

\section{Las primeras colonias para niños débiles en la Argentina}

El debate sobre el significado y las propuestas de creación de estas primeras colonias se da en el marco de las consecuencias sociales del proceso modernizador y de expansión económica del país de fines del siglo XIX que impactó en políticos e intelectuales preocupados por la "cuestión social" - que abarcaba asuntos resultantes de la alta tasa inmigratoria, urbanización acelerada e industrialización - interpretada como conjunto de problemas objetivos y cuantificables estadísticamente, además de un desafío intelectual, un elemento clave en las transformaciones políticas e ideológicas de la primer década del siglo XX. Ideas sobre la evolución de las instituciones políticas y sociales, y sobre la relación entre el Estado y la sociedad fueron dominadas por un nuevo espíritu de reforma (Zimmerman, 1992). En este marco de ideas se realizaron muchas construcciones del Estado - escuelas, hospitales, cárceles - edificios que sin duda constituyeron antecedentes - formales o tipológicos - para las primeras colonias.

Repasemos brevemente lo que la bibliografía refería a principios del siglo XX sobre las colonias de vacaciones. En relación al origen, es el pastor evangelista suizo Walter Bion considerado el fundador de las colonias escolares de vacaciones. En 1876 llevó 68 niños pobres al cantón de Appenzell al campo y pasaron allí dos semanas respirando aire puro y recibiendo alimentación sencilla y fortificante. Su experiencia tuvo tanto éxito que en pocos años se extendió a Europa y América (Pereyra, 1982). Así en Buenos Aires, el Monitor de la Educación Común reproducía, en 1908, un artículo de la Revue Pédagogique sobre las colonias escolares de vacaciones. Se explican allí sus efectos: en primer lugar sobre la salud, siendo por tanto propicio escoger niños débiles, flacos, anémicos, raquíticos, los más expuestos a enfermedades, especialmente tuberculosis, para mandarlos a un medio favorable a hacer músculos, enriquecer su sangre, acrecentar su poder de resistencia, preparando los organismos para luchar contra 
las deficiencias físicas. La eficacia de la permanencia al aire puro, en una duración mínima de 35 días, aseguraba aumento de peso, de estatura y ganancia de glóbulos rojos en la sangre.

En segundo lugar se advertía acerca de las consecuencias sobre la inteligencia, el humor, el poder de atención, la alegría y la flexibilidad de espíritu. Finalmente, sobre la moralidad. La regeneración física de los niños aumentaría también su poder de reflexión, de acción y de decisión. Propone una cuidada y regulada alimentación. Culmina el estudio con las condiciones que debían tener las colonias escolares, aspectos resumidos en una duración de 35 a 40 días. Con respecto al alojamiento distingue entre las colonias de internado, en edificios en pleno campo, o el alojamiento familiar. Finaliza: si queremos combatir la expansión de la tuberculosis, enfermedad social, es desde el niño, que hay que reconocerla y combatirla (Gehin, 31 mar. 1908).

Otro ejemplo de la misma publicación introduce las conclusiones vertidas sobre el tema por José Ingenieros ${ }^{1}$ (1907), de las que destaca: que el objetivo de las mismas era médicopedagógico y no recreativo. Que debían elegirse los niños débiles y enfermizos y no los mejores alumnos, en tanto la colonia era un tratamiento y no un premio. Entendía esencial la institución de una ficha antropológica escolar, como medio fundamental para apreciar los resultados de las colonias de vacaciones, supeditando el éxito a la cooperación entre médico y maestro. Finalmente, la heterogeneidad de raza y cultura de nuestra población rural hacían preferible las colonias de internado sobre las familiares.

Experiencias tempranas de colonias de internado fueron realizadas por la Asociación Colonias de Niños Débiles y Preventorios Infantiles, dependientes de la institución católica Escuelas y Patronatos, ${ }^{2}$ la que contaba con "establecimientos de llanura, mar y montaña, para llevar al niño débil, convaleciente o pretuberculoso, sacándolo, casi siempre, del conventillo ... medio malsano para su salud física y moral" (Escuelas..., 1937). La institución - con personería jurídica desde 1907 - buscaba encaminar moral e higiénicamente al niño, procurando en sus colonias fortalecer su cuerpo, educar su mente y elevar su alma. Podemos mencionar, entre otras, la Colonia Eloísa Ponce de León de Ezpeleta fundada en 1907 como preventorio infantil permanente para varones en Bella Vista, provincia de Buenos Aires. En 1908 se funda en Santos Lugares (provincia de Buenos Aires) la Colonia Santa María, preventorio infantil permanente para mujeres. En Río Ceballos - Córdoba - se funda, en 1916, Centenario, colonia veraniega para varones. En 1924, y también para varones, se crea la colonia agrícola y veraniega Reynaldo Otero, en Pergamino (Buenos Aires). Ese mismo año se funda, en Quequén (Buenos Aires), la colonia Guerrico como veraniega para ambos sexos pero alojados por turnos.

Por iniciativa del director general de Escuelas de Mendoza, sr. P. Antequeda, y en el marco de la reforma educativa para la provincia y su plan de edificación escolar, se proyecta, en 1915, la Colonia Nacional de Vacaciones para niños débiles y maestros desgastados, a construirse en Uspallata - valle de excelentes condiciones térmicas - en un solar próximo a la estación y a 1.800 metros de altura, con una superficie de 350 hectáreas. Según refiere el arquitecto Andrés Tosi (1915), ${ }^{3}$ autor del proyecto, buscó armonizar la arquitectura de la edificación con la región, proyectándola "estilo chalet suizo". El edificio, con una superficie aproximada de 60 mil metros cuadrados, se implantaría en medio de árboles, donde predominaban los pinos por higienizar el aire en grado sumo con su oxígeno. 
Un planteo simétrico alterna llenos y vacíos, en un mero ejercicio compositivo, diferenciando cinco partes: el acceso, tres sectores de similares dimensiones pero compositivamente distintos y la capilla como remate en una secuencia a través del eje central de la composición, el que tenía una desviación respecto al norte verdadero para garantizar - según preceptos higiénicos - un amplio asoleamiento, sin recibir nunca los rayos directos del sol, pero maximizando la exposición solar (Imagenes 1, 2).

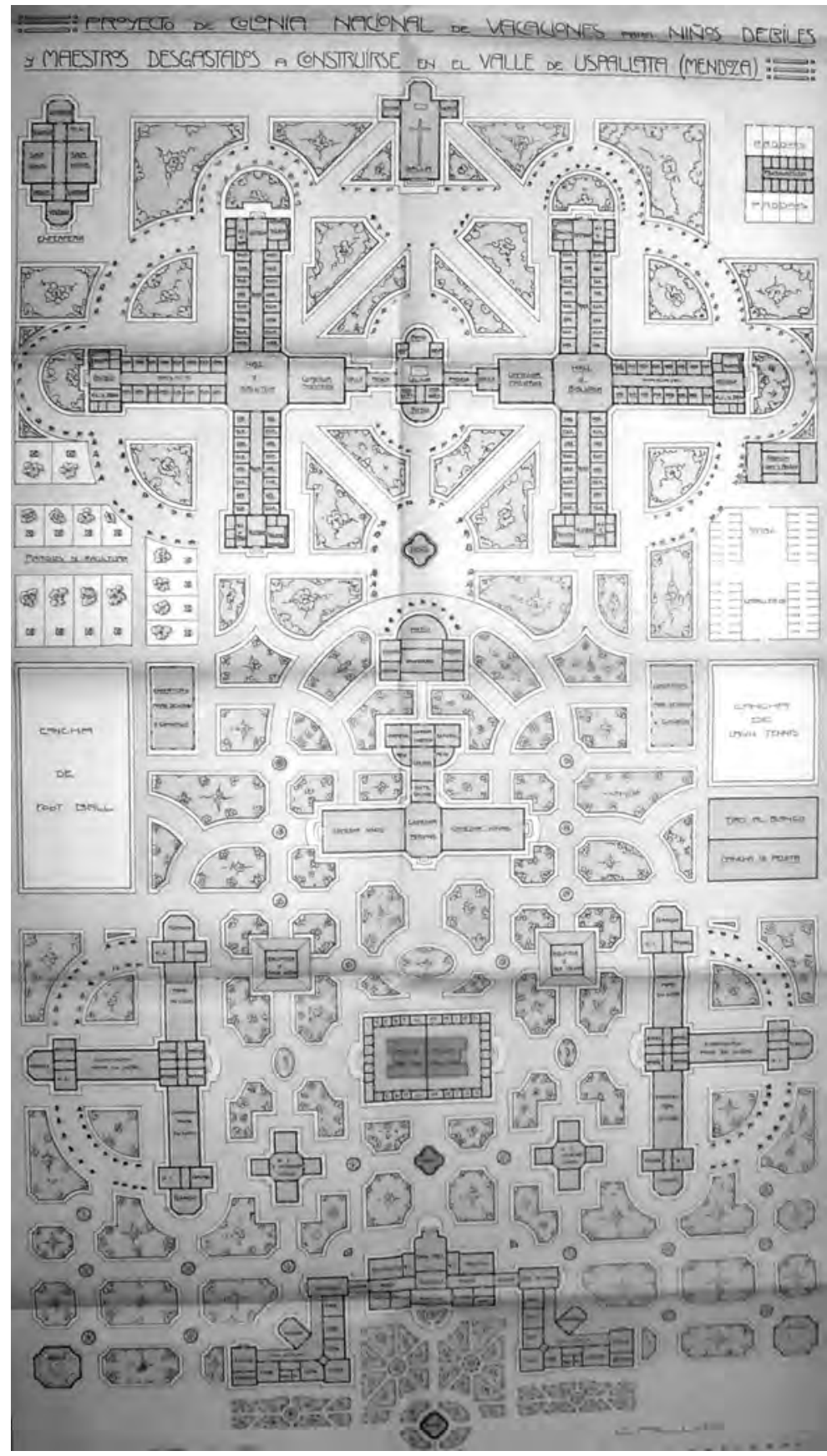


La vida en la colonia se organizaba desde las siete de la mañana y concluía alrededor de las diez de la noche con música, baile y juegos; contaban con suculentas comidas y medidas profilácticas, dispuestas por la directora, quien refería, que reinaba en la colonia un sistema de igualdad absoluta entre ellas. Todas trabajando para todas cual si fuera una gran familia reunida en un gran hogar.

\section{Baños de sol y mar: Colonia Marítima de Necochea}

Como vimos, las colonias de vacaciones se clasificaban, según el clima, en marítimas, de llanura y de montaña. Nos ocuparemos aquí de las primeras, tomando como caso de estudio la Colonia Marítima de Necochea. El dr. Luis Boffi (1930), ex médico de la citada institución, definía las colonias de vacaciones como el - eslabón final de la cadena profiláctica ${ }^{4}$ contra la tuberculosis - establecimientos alejados de las ciudades y de toda edificación, donde enviar a los niños a pasar los meses de verano.

Consideraba, asimismo, este profesional, tres factores naturales de influencia capital en la vida de los niños en las colonas marítimas: el clima, la acción del sol y los baños de mar. En referencia al clima, expresa que la localización de las dos colonias marítimas que existían en ese momento - la de Necochea y la de Mar del Plata -, en tanto parte saliente de la costa bonaerense, gozaban de todas las bondades del clima marítimo, con su acción tónica y excitante, lo que las convertía en el gran clima para todos los niños, hijos de tuberculosos o no, catalogados en el grupo de las diátesis: los débiles, raquíticos, linfáticos o adenoides.

Continuaba el dr. Boffi explicando que la acción del sol, como consecuencia de la influencia de los rayos químicos de la luz, modifica las funciones celulares, teniendo además influencia bactericida. La superficie líquida del mar refleja los rayos químicos y absorbe los calóricos, optimizando los beneficios sobre el ser humano. Finalmente, en el baño de mar baño frío a lo que se suma la acción percutora de las olas - intervienen elementos de capital importancia como el aire marino, la luminosidad del ambiente, las condiciones del clima y la composición del agua. Finalmente, estas nociones científicas de clima, sol y baño de mar debían ser tenidas en cuenta para la construcción de una colonia y para el comportamiento del médico entre sus pequeños asilados.

Por iniciativa del diputado nacional por la Unión Cívica Radical, Leopoldo Bard - médico y fundador del Club River Plate - se creó la Colonia Marítima de Necochea - financiada por la Nación - pasando el establecimiento terminado a disposición de la Municipalidad de la capital federal y se incluye en 1928 - dirigida por el dr. Alejandro Raimondi - en el plan general de lucha antituberculosa del Hospital Tornú. Así en el Dispensario Central de Vías Respiratorias, que funcionaba en dicho hospital, se abre un registro de inscripción de niños débiles y se reglamenta su organización y funcionamiento. La colonia funcionaría de noviembre a abril, admitiendo niños de ambos sexos: mujeres entre 8 y 12 años y varones de 8 a 10. Tendrían preferencia en la admisión, los niños internados en el preventorio Roca. 
El reglamento enumera las actividades a desarrollar y los horarios de las mismas, iniciándose al levantarse a las siete de la mañana - limpieza y aseo - seguidas del desayuno, para salir luego a la playa, donde se realizaba una hora y media de aéreo y helioterapia, gimnasia general y juegos, seguidas de media hora de balneoterapia. Regreso a la colonia para almorzar a las 11h30. Descanso hasta 14h30, luego baño de higiene, recreo en el patio seguido de la merienda. De cuatro a seis de la tarde se volvía a la playa para realizar aéreo, helioterapia y juegos. Terminaban las tareas diarias con la comida a las sete de la noche y silencio a las ocho (Raimondi, 1930).

Un médico interno residía en la colonia y tenía a cargo la vigilancia de higiene y salud de los niños, además de llevar una ficha con datos biográficos y antropométricos. Un dentista se ocupaba de la higiene bucal, y ambos debían cumplir con las tareas pedagógicas de explicación de la importancia y las formas de cuidado e higiene. Finalmente, la alimentación de los niños debía ajustarse también a una dieta regulada por ración individual para cada comida y organizada en un menú semanal. La colonia proveía asimismo de ropa a los niños residentes, y el transporte estaba a cargo de la comuna.

El proyecto del edificio para la colonia se inicia en 1923 en dependencias de la Dirección de Arquitectura de la Nación y tuvo diversas modificaciones y ampliaciones. El terreno, de superficie equivalente aproximada a dos manzanas, se sitúa sobre la avenida costanera de lo que hoy es la villa veraniega, por entonces aislado de la zona poblada, desbordando sobre la playa. Originalmente se proyectaron dos pabellones, habilitándose el primero en 1928 y el segundo en 1929. Cada uno, implantado con el lado más largo frente a la playa - con una superficie aproximada de $1.700 \mathrm{~m}^{2}$. Constaba de tres plantas: el centro de la planta baja era ocupado por un comedor y abastecido por los servicios de cocina etc. A cada lado del mismo, flanqueados por zonas de acceso - las que remataban en las circulaciones verticales - se encontraban salones de juegos. Las dos plantas para los dormitorios tenían capacidad para 250 camas. El primer nivel estaba destinado a las niñas y presentaba en un extremo el aposento para el médico interno. En el otro nivel se ubicarían los varones y las celadoras. El interior de los pabellones es simple y luminoso, dejando a la vista las columnas de hormigón en el comedor; los dormitorios se organizan por dos hileras de boxes separados por tabiques y abiertos a una circulación central. Durante los años 1930 se completó con distintos pabellones de servicios y otras dependencias, todo rodeando el vacío central (Imagenes 3, 4).

Puede vincularse esta disposición de los distintos pabellones en un espacio verde con el anteproyecto mendocino, aunque ahora la escala es menor y el programa responde a otra realidad: sin piscinas, ni bibliotecas, ni canchas de tenis, ni campos de tiro, la playa era el lugar de las actividades lúdicas y recreativas. En sus fachadas se leen claramente las distintas partes: el piso bajo de las actividades públicas presenta sobre la calle amplios ventanales a modo de galería cerrada, interrumpida por los volúmenes de acceso, con carpintería de arco de medio punto y rematada por torres techadas a cuatro aguas. Las ventanas de los dormitorios, distintas en los dos niveles, son unificadas con la obra en ladrillo visto.

Finalmente, debe destacarse la cuidada factura de los dos edificios originales, que se preservan sin alteraciones en su estética modernista. Sus muros revocados presentan un elaborado trabajo en ladrillo rojo - destacando los vanos, las torres y el piso bajo - lo que junto a los techos de tejas - con su también elaborada tirantearía de madera - perpetúan su imagen típica. 
y Miramar - ramblas, paseos y avenidas - un primer impulso forestal con la organización de viveros, la realización de parques públicos y museos históricos, que se completa con la pavimentación de rutas. Sintéticamente estaban definidos una serie de puntos de interés turístico - cultural y natural - sobre el territorio provincial: establecimientos ganaderos y ranchos pampeanos reproducidos en los museos gauchescos, la piedra movediza en las sierras de Tandil, el abra del sistema serrano de Ventanía, la costa rioplatense y poco más de una docena de balnearios marítimos fundados por empresarios y dueños de los campos, todo enlazado por una precaria red de caminos pavimentados, mejorados o en construcción.

En el plano educativo los objetivos del gobernante fueron luchar contra el analfabetismo y el enciclopedismo. La escuela debía, además, estimular sentimientos patrióticos, nacionalistas y religiosos. Así, con el fin de elevar el índice racial de la población infantil y en procura de una enseñanza integral se crea la Dirección General de Educación Física y Cultura de la provincia de Buenos Aires. Se consideraba entonces que la educación física no podía ser un agente aislado en el proceso evolutivo del niño, sino formar parte de la enseñanza en su triple aspecto "moral, intelectual y físico". El deber del gobierno era estimular y orientar a los jóvenes en la práctica de ejercicios físicos y deportes, que fueran además de una actividad muscular, un factor decisivo en la educación del espíritu.

Otra característica de gobierno fue la realización de obras públicas y en esta materia, planifica para 1938 la realización de 195 edificios escolares. Habilita comedores escolares, estadios, campos de deportes y clubes de niños en los distintos distritos de la provincia, además de poner en marcha el sistema de vacaciones para alumnos, dando nuevo impulso a las colonias de vacaciones.

Con el propósito de mejorar el fortalecimiento de los escolares, se extendió entonces el radio de estos establecimientos a las tres categorías que señalaban los tratadistas y que coincidían además con las zonas de turismo del territorio provincial: mar, sierra y llano.

La dirección del cuerpo médico escolar seleccionaba los alumnos que se beneficiarían del descanso en cada período y se ocupaba de la dirección y organización de las colonias. Se consideraban temas relevantes tanto el régimen alimenticio - cantidad y calidad - de los nutrientes y el método de vida a seguir, para lo cual, de la misma forma que el caso anterior, las actividades estaban organizadas para las distintas horas del día y de la noche. Adquirían también relevancia en la vida en las colonias las cuestiones vinculadas con la higiene personal y colectiva y el tipo de ejercicios físicos adecuados a los colonos.

Muchas de estas actividades de los colonos han quedado documentadas por las fotografías que muestran grupos de niños con guardapolvos blancos, paseando por la rambla en Mar del Plata o descansando en la playa antes de tomar el baño; supervisados por maestros y enfermeras, realizando series de gimnasia calisténica, guiados por un profesor, o tomando baños de mar y de sol, de forma "metódica y científica". Otras imágenes muestran niños en fila marchando por la sierra o jugando en plazas y parques, además de almuerzos en largas mesas en los comedores (Imagenes 5, 6).

Paradójicamente no se registran edificios realizados para este fin por la provincia, sino que las colonias funcionaban generalmente en las escuelas. Mencionemos, como ejemplo, Punta Lara junto al río de La Plata; Mar del Plata, Necochea y Miramar, las tres colonias marítimas. Y las serranas en Tandil y Sierra de la Ventana. 


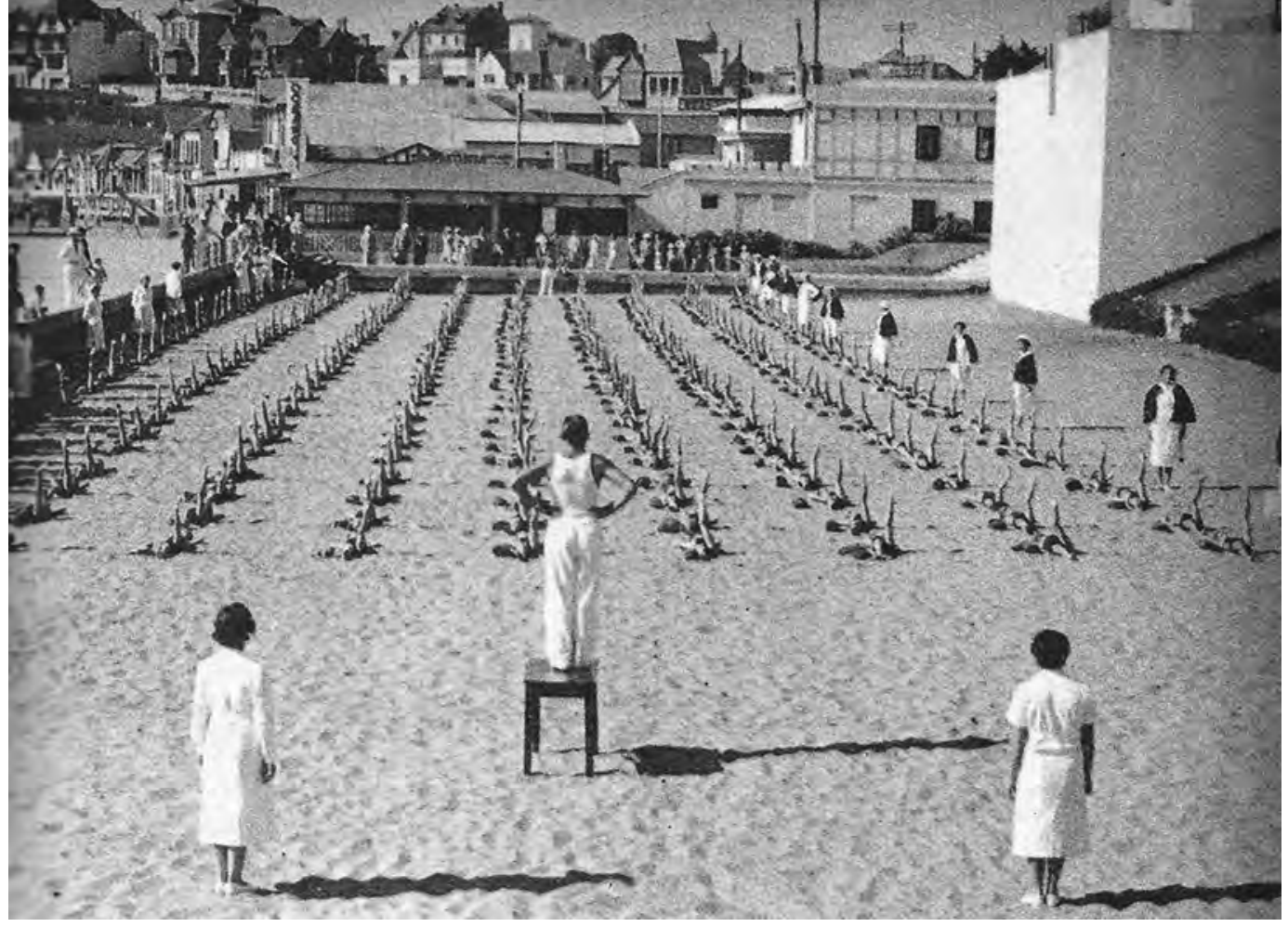

Imagen 5: Ejercicios de gimnasia calisténica en la playa, alumnos de la colonia de Mar del Plata (Provincia..., 1940)

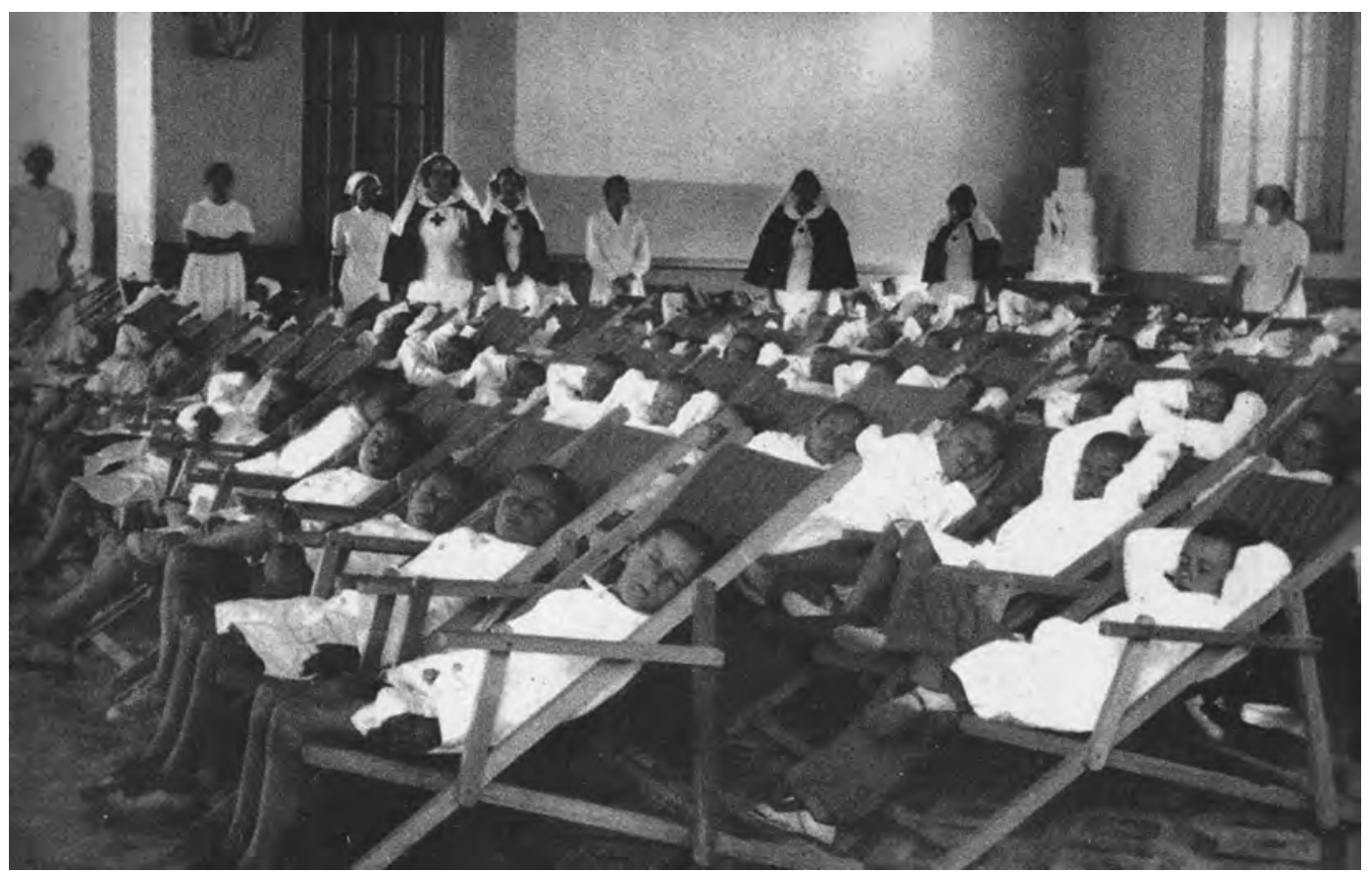

Imagen 6: Colonos descansando a la hora de la siesta (Provincia..., 1940)

Las fuentes gubernamentales consideraban halagüeños los resultados y exponían que además de otros síntomas, el aumento de peso oscilaba entre un 77,10 a un 91\%. Las ventajas en el orden intelectual de estos niños se comprobaban en el regreso a las aulas con una mejora en su ánimo y en las disposiciones adquisitivas, sin duda "efectos beneficiosos, esa alegría de vivir, que transmite el contacto con la naturaleza, el respirar aire puro a pleno pulmón". 


\section{Colonias de vacaciones del Consejo Nacional de Educación}

Paralelamente, en la segunda mitad de los años 1930 comienza una nueva etapa de las colonias de vacaciones dependientes del Consejo Nacional de Educación (CNE) con la construcción de edificios concebidos específicamente para tal fin, como lo refiere el dr. Enrique Olivieri, director del cuerpo médico escolar - profesor adjunto de la Facultad de Medicina en una extensa nota sobre la historia y evolución de estas colonias publicada en el Monitor de la educación. Se extractarán de allí aspectos relevantes para este estudio.

Las colonias de vacaciones que sostenía el CNE, en su organización higiénica social, pasaron por dos etapas. La primera se inicia en 1924 - en 1895 se había llevado un primer contingente pero quedó como hecho aislado sin continuidad inmediata - con el envío a Mar del Plata de doscientos escolares, número de niños beneficiados que fue aumentando hasta que en 1928 llegó a 770. Esta colonia con funcionaba en una escuela céntrica frente a la Plaza Luro - cedida por la provincia de Buenos Aires - en la que se hacían cada año las obras de adaptación necesarias. En ese año se solicita al presidente del Consejo - dr. Enrique Mosca - la ampliación de las colonias de vacaciones para cubrir además otras necesitadas, devenidas de agrupar los niños de la siguiente manera:

Los niños débiles de nuestras escuelas, señor presidente, a los efectos del tratamiento climatérico, son clasificados en tres tipos clásicos conocidos: niños débiles a quienes favorece el clima de mar; niños a quienes beneficia el clima de llanura; y aquellos a los que el tratamiento climatérico de la montaña les está indicado por los resultados que se obtienen (Olivieri, 1939).

En este campo de ideas, entonces, se establece en noviembre una colonia de llanura en Baradero y luego una de montaña, en Tandil, en una escuela cedida por la provincia, completando así las necesidades de los tres tipos; la de mar para los adenopáticos, escrofulosos, etc.; la de llanura para los nerviosos y destruidos por insuficiencia de medio y vivienda; montaña para los bronquiales, asmáticos y anémicos. Luego se instalaron también colonias en Caruhé, Mina Clavero - provincia de Córdoba - y Ciudadela.

En 1930 las colonias de vacaciones fueron suprimidas del presupuesto por razones de orden económico y dejaron de funcionar, cerrándose así esta primera etapa, en la que todas las colonias funcionaron en edificios escolares, cedidos por la provincia, con los problemas que esto conllevaba.

Surge entonces la necesidad de construir edificios apropiados para el funcionamiento de las colonias del consejo, tal como lo había hecho la Municipalidad de Buenos Aires con la construcción de la colonia de Necochea. El restablecimiento de las partidas presupuestarias en 1935, y las construcciones apropiadas, marcaría el inicio de una segunda etapa en que se extendió además el beneficio a todo el país, ya que hasta entonces solo alcanzaba para alumnos de la capital de la República, adquiriendo así la obra carácter nacional. ${ }^{5}$

La visita a Tandil del presidente del Consejo, del director del Cuerpo Médico y del administrador posibilitó comprobar el estado deficitario de los locales, a la vez que vislumbrar posibles terrenos donde localizar los nuevos edificios. Se resuelve entonces la construcción de la de Tandil en una chacra que el Consejo poseía; en Mar del Plata los empresarios del casino sres. Marchinandiarena y Sola - donaron dos manzanas y con proyecto de la Dirección General 
de Arquitectura del CNE - por esos años a cargo del arquitecto Alberto Gelly Cantilo ${ }^{6}$ - se inicia, en 1937, en el balneario, la construcción de una colonia con capacidad para quinientos niños que luego se ampliaría a mil. Con capacidad para trescientos escolares y con idénticas características y comodidades se construyeron edificios en Tandil y en Alta Gracia, en terreno donado por el ex vocal dr. Nicolás Avellaneda. Se compró también un edificio donde funcionó una colonia en Baradero.

Como en los casos anteriores, las colonias contaban con una organización interna con horarios que comenzaban con el desayuno a las 7 h30 y la hora del silencio a las 20h30. Regímenes de alimentación con menús diarios, lo que junto con las condiciones climáticas constituían la base fundamental para la recuperación de la salud de los asilados. Se proveía también de ajuar de ropa y utensilios de aseo.

El médico organizaba la distribución del tiempo en la vida de las colonias, a partir de un tiempo de adaptación de los niños al nuevo ambiente, la dosificación de la helioterapia y balneoterapia. Al momento del ingreso, como hemos visto en otros casos, se realizaba una ficha con los antecedentes sociales, hereditarios e individuales y se registraban además los datos del examen antropométrico.

Los resultados de esta obra de "solidaridad social y sano nacionalismo" eran prueba del valor de las colonias desde el punto de vista higiénico:

Aumento de peso promedio de dos kilos, alegría, adquisición de prácticas higiénicas y vivacidad en los rostros marcados antes por los signos de la debilidad. Pero, además, los niños de las diversas regiones alojados en las colonias establecían una compenetración espiritual que favorecía la unidad de la nación, llevando en sus mentes juveniles un recuerdo imborrable de la grandeza de la patria (Olivieri, 1939, p.79).

El edificio de la colonia de vacaciones de Mar del Plata - inaugurado en 1937 - se levantó en una de las dos manzanas de las que se disponía. Más tarde se ampliaría la obra en la otra. La disposición general responde a una organización claustral en torno al patio central de cuarenta metros por lado. Contaba con salones destinados a patio cubierto, comedor y dormitorios unidos internamente, en los que se tuvo en cuenta, además, la correcta ventilación, el asoleamiento y la protección contra los vientos fríos del sud y sudeste. Completan la planta las oficinas para dirección y secretaría, consultorios médico y odontológico; servicios de cocina y office, habitaciones para el personal, local para lencería y ropa blanca, pabellones sanitarios con lavatorios, water closet, vestuarios y duchas. Desde el hall de acceso se toman las escaleras que permiten alcanzar los dormitorios para profesores, ubicados en la segunda planta y jerarquizando, con esta parte más alta, el acceso al edificio. Además, en una construcción independiente había enfermería y aislamiento, servicio de lavado y planchado y un garaje para dos coches, con pequeño taller y depósito anexo (Imagen 7).

Aquí los pabellones para dormitorios se disponen sobre los bordes de la manzana rodeando el patio central. Las distintas partes se han compactado, ahorrando circulaciones. Los salones dormitorios se han también simplificado: la carencia de cielo raso deja a la vista las cabreadas del techo, no hay muros divisorios y se disponen una cama contigua a la otra. La arquitectura exterior es austera, de simples líneas, con muros revocados, carpintería de madera y techos a dos aguas. Sin duda, la obra de la colonia representa los conceptos de edificación escolar 


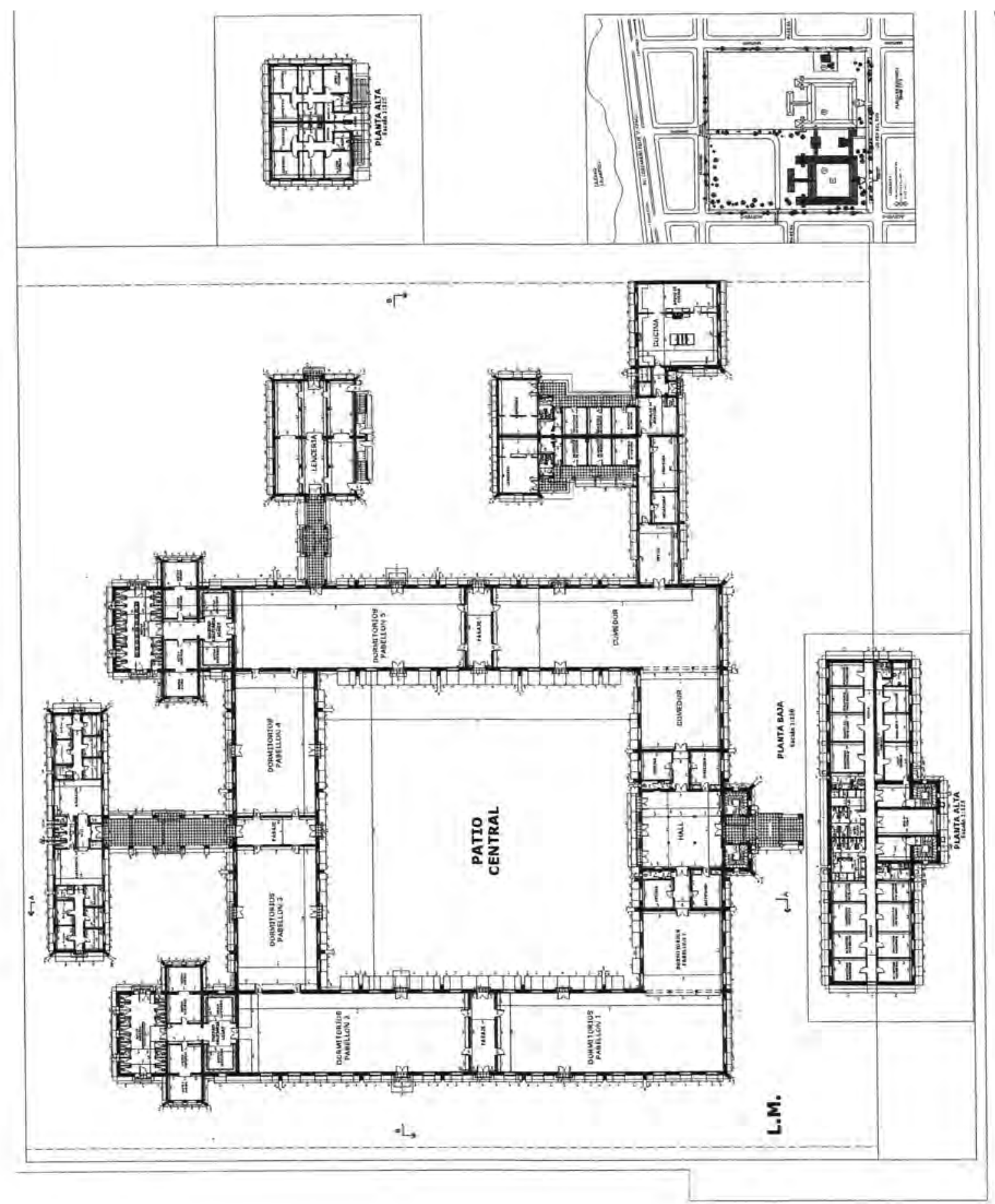

Imagen 7: Planta de la Colonia Marítima de Mar del Plata del Consejo Nacional de Educación (Gentileza arquitecto Juan José Garamendy, Universidad Nacional de Mar Del Plata, Mar del Plata) 
de la Dirección de Arquitectura: ${ }^{7}$ materiales seleccionados por economía y durabilidad y empleados de forma razonada para proveer su estructura y servir a la vez de decoración, "habilitando edificios sencillos, bien asoleados, y distribuidos de acuerdo a las exigencias higiénico-pedagógicas recomendadas por la ciencia moderna" (Conceptos..., feb. 1935).

\section{Turismo social y obra pública: hoteles y colonias en el territorio provincial}

Puede decirse que es a partir de los años 1930 cuando el Estado - en sus distintos niveles, nacional, provincial y municipal - incorpora las actividades turísticas como orientador de sus políticas, buscando tanto su progresiva organización así como la realización de obras de infraestructura que hicieran posible la extensión de la actividad a grupos cada vez más amplios de población. Se entiende así, que como complemento de las licencias anuales de descanso, debía el Estado crear lugares apropiados para camping y colonias de vacaciones, necesarias no sólo para niños débiles, sino también para la población adulta del país. Con la disposición de numerosas colonias de vacaciones en los distintos puntos del país, además del descanso reparador, se favorecería el desarrollo de la industria del turismo: "exportación al interior", como se la llamaba en Francia, o "exportación invisible", como se la designaba en Italia.

En los años 1940 el turismo es considerado definitivamente una necesidad nacional, constituyéndose como problema de Estado, y en ese sentido, además de la celebración del Congreso Nacional, debe mencionarse la creación de la Comisión Nacional de Turismo, con carácter honorario y en dependencia directa del Ministerio de Agricultura de la Nación. Constituye, asimismo, un Comité Consultivo Honorario integrado por representantes de entidades públicas y privadas, vinculadas a la actividad en el país. En junio de 1942 pasa a denominarse Dirección Nacional de Turismo y se establece su régimen orgánico. Fusionada más tarde con la Dirección de Parques Nacionales, y con atribuciones limitadas, prácticamente su actividad se redujo a la organización de excursiones aisladas y a la fundación de la Escuela Hotelera para la formación de personal idóneo. En este marco no puede dejar de mencionarse la sanción de la ley 12.669/1940 de construcción de hoteles y hosterías de turismo, siendo su aplicación herramienta primordial del Estado nacional en favor del turismo en el país.

Aunque no se analizará aquí, debe mencionarse que la primer colonia para empleados nacionales se realizó en Embalse Río Tercero, Córdoba, organizada en 1936 a instancias del ex secretario de la Presidencia de la Nación Alberto Merello. En 1937 el Ejecutivo nacional creó la Comisión Nacional de Colonias de Vacaciones para empleados nacionales. Contaba con una capacidad de cuatrocientos plazas, distribuidos en dos pabellones, divididos en departamentos de dos y tres dormitorios, además de casitas con capacidad para cinco a diez personas (Desmarás, 1942).

Luego, el Ministerio de Obras Públicas de la Nación y su ministro Pistarini ampliarían la obra de Córdoba e iniciarían las obras en Chapadmalal, que luego continuaría la Fundación Eva Perón. La Colonia de Vacaciones de Chapadamal - paraíso de los humildes - contó con nueve hoteles con capacidad para alrededor de sietecientas personas cada uno (Imagen 8). Estas colonias hacían posible el descanso no solo de los niños sino de las familias completas, favoreciendo así la unidad familiar. Y en referencia a la vinculación a las colonias y a la salud decía el ministro Pistarini en el acto inaugural, en Río Tercero: "La atención médica de 
nuestros empleados y obreros será mejorada mediante la construcción de policlínicos, pero estimamos que hay que dar prelación a los establecimientos preventivos, porque más vale prevenir que curar" (Argentina, 1947).

En la provincia de Buenos Aires fue el gobernador Domingo Mercante quien, con el objetivo político de elevar el standard de la vida proletaria, otorga al turismo en general, y fundamentalmente el turismo social, un lugar relevante en su gestión de gobierno. Debe consignarse aquí que por esos años el turismo social - si bien se había generalizado en el mundo - no se tenía todavía una noción exacta del mismo, pudiendo definirse como "el conjunto de relaciones y fenómenos de orden turístico, resultantes del hecho de la participación en el turismo de las clases económicamente débiles" (Ministerio..., 1956, p.20), siendo entonces el que realizaban los sectores de la población que no podían acceder a las formas tradicionales de hacer turismo. Difiere entonces del turismo general por la utilización de distintos medios de transporte y formas de alojamiento, pero la finalidad sigue siendo en ambos casos la realización de viajes que tendieran al mejoramiento físico y a la elevación intelectual y cultural del individuo.

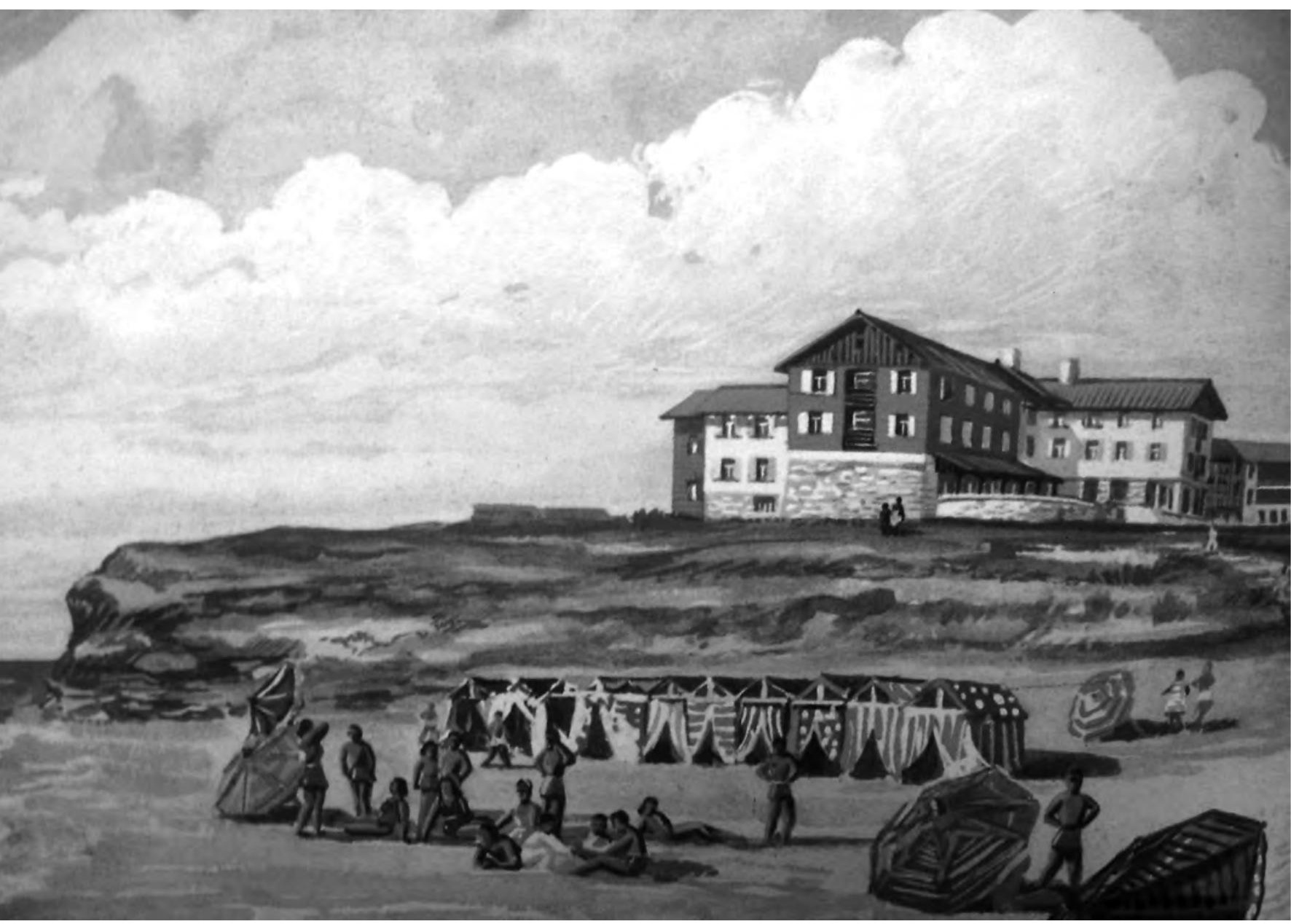


Reconociendo en el turismo una "cuestión social de incumbencia estatal", y con el propósito de reorientar y fomentar las múltiples actividades turísticas dentro del territorio provincial, el Ejecutivo propone, en julio de 1946, la creación de la Dirección de Turismo, Caza y Pesca de la Provincia en dependencias del Ministerio de Obras Públicas. Con modificaciones, se convierte en la ley 5.254 en 1948, creándose la Dirección de Turismo y Parques de la Provincia de Buenos Aires, dependiente del Ministerio de Hacienda, Economía y Previsión, la que tendría a su cargo todo lo referido al desenvolvimiento del turismo. Sus fines principales eran la conservación de las zonas de turismo, así como proteger las bellezas naturales, las fuentes de salud o termas, la flora, la fauna y todo lo que constituya fuente de atractivo turístico. Crear y habilitar lugares de sosiego; impulsar el turismo social para facilitar el descanso a un mayor número de personas, organizando campamentos económicos y colectivos. De sus funciones se destaca la organización y el fomento de actividades sociales, culturales, deportivas, artísticas, evocativas, certámenes, exposiciones o muestras, a fin de conocer las riquezas y características de la provincia, su producción e industria.

El Ejecutivo sintetizaba su pensamiento en materia turística en un triple planteo que incluía el Turismo Social, el Turismo Cultural, y la Industria Turística. Urgido por actuar en la materia, y mientras la legislatura no se había expedido sobre su iniciativa inicial sobre turismo en la provincia, el gobierno decide otras medidas con mayores precisiones y pragmatismo, decretando las zonas de turismo dentro del territorio provincial: Mar y Sierra, Cruz del Sur, Zona de las Lagunas y Norte y Delta.

En 1949 inauguraba la Asamblea Legislativa el gobernador Mercante ya persuadido de haber impreso un carácter "social" al turismo, posibilitando y organizando el traslado de los sectores populares a lugares aptos para la contemplación estética. Definía entonces el "turismo social como la organización oficial que, aprovechando la atracción del hombre de la ciudad por el paisaje natural, considerando el bienestar moral y físico que le acarrea y valiéndose de la rapidez y velocidad de las comunicaciones, da un impulso decisivo a la afición por las vacaciones recreativas entre las masas de trabajadores de la Provincia" (Mercante, 1950, p.16).

Y al año siguiente, habiéndose ya sancionado la Constitución de 1949, la labor en materia de turismo social es considerada el complemento del precepto constitucional que hace del paisaje natural "patrimonio cultural de la nación". No es tema para desarrollar aquí, pero gran número de personas hicieron uso de los planes de turismo social, difundidos, entre otras formas, mediante el slogan "usted se paga el viaje la provincia el hospedaje".

Resta por último hacer referencia a la industria turística que el gobierno resumía, primariamente, en la construcción de hoteles de turismo mediante obra pública, cuyo objetivo era crear centros o zonas de interés para la iniciativa privada, fortaleciendo la economía del estado provincial, aumentando su riqueza en la medida que pudiera ser redistribuida en todas y cada una de las clases que contribuyeran a crearla.

El Plan Inicial de Trabajos Públicos - ley 5.079, de noviembre de 1946 - tenía por propósito realizar obras consideradas de especial urgencia, asignando una suma relativamente importante, en comparación con otros rubros, a la construcción de hoteles económicos y campamentos en zonas de turismo en Carhué, Chascomús, Miramar y Sierra de la Ventana, por un lado, y hotel Provincial de La Plata, en la ciudad capital. 
De igual forma, el Plan Trienal incluye la realización de obras de arquitectura para el fomento del turismo, ordenadas en el territorio provincial en busca de un cierto equilibrio y redistribución de los grupos de acuerdo a las posibilidades de cada lugar, determinándose consecuentemente tres categorías.

Así, el proyecto de construcción de hoteles de turismo llena un vacío del estado provincial en materia turística, dado que, salvo el Hotel Provincial de Mar del Plata proyectado durante la gobernación de Fresco, en el marco de las obras de urbanización de Playa Bristol, y terminado en la década siguiente, el resto de los hoteles del territorio provincial habían sido construidos por particulares. Aunque esta infraestructura hotelera no se completó de la forma prevista, erigiéndose solo algunos edificios, tema aún no suficientemente estudiado.

Sí se construyeron, en cambio, centros de salud para escolares, en colonias de vacaciones, de las que se han registrado una en Tandil y otra tipo llanura, en el balneario Monte Hermoso, cuyo edificio observaremos finalmente a modo de cierre de este recorrido.

\section{Colonia Monte Hermoso}

El proyecto pertenece a la Dirección de Arquitectura del Ministerio de Obras Públicas de la provincia de Buenos Aires, fechado en agosto de 1948. Las obras de esta repartición provincial no han sido aún muy estudiadas, fundamentalmente por la dificultad de acceso a sus archivos.

El edificio de la colonia se organiza en tres plantas, con una superficie total de poco más de dos mil metros cuadrados. Se implantó en una manzana rectangular, de amplias dimensiones y próximo a la playa. Se accedía por la planta baja a través de un patio cubierto. La entrada dejaba a cada lado sanitarios de varones y mujeres, para luego dar lugar a una circulación que permitía el acceso al salón comedor, a una zona de administración, a las dos escaleras que comunicaban con los pisos superiores y, finalmente, a una zona de servicios con cocina, habitaciones para el personal y sala de máquinas y calderas, por lo que se deduce que resolvía aspectos de confort con la provisión de calefacción central. Cada escalera permitía el acceso a los dormitorios de niñas con sus locales sanitarios, en un amplio pabellón con capacidad para 72 camas, y la otra a los dormitorios de varones, los que se distribuían en dos plantas con 48 camas cada uno. El último piso contenía también consultorios y salas de enfermos, separadas por sexo (Imagenes 9, 10, 11).

Contaba con una clara disposición en el armado de las distintas funciones, la volumetría expresaba también en el exterior las distintas partes del edifico. Alterna muros revocados con otros de ladrillo visto, techos de tejas a dos aguas en las alas de los pabellones y las ventanas de los dormitorios con cortinas de enrollar. Realizado sobre el final de los años 1940 se advierte una organización en planta que busca racionalidad y economía, lograda con una planta baja "en cruz" que concentra los servicios centralmente, habilitando locales de uso público bien orientados, iluminados y ventilados. 


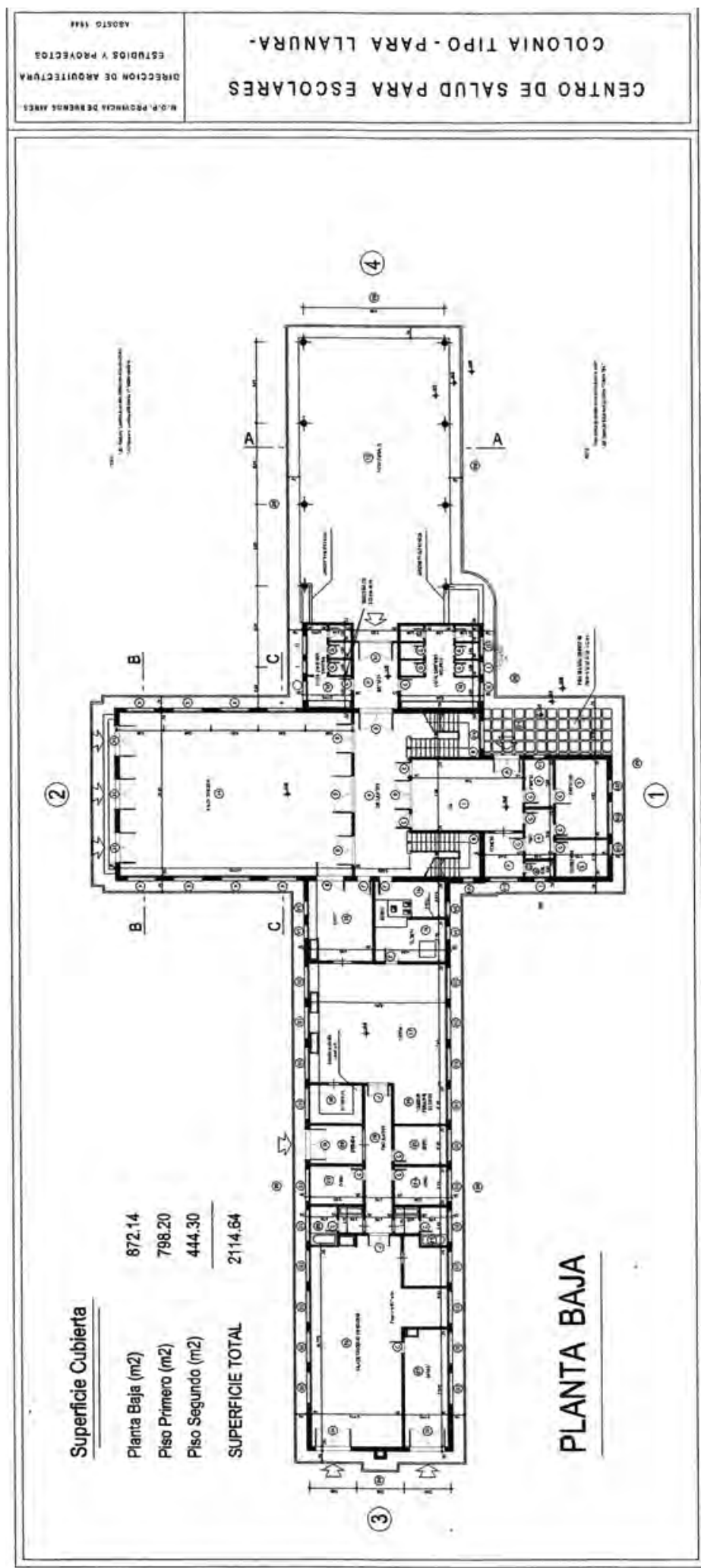




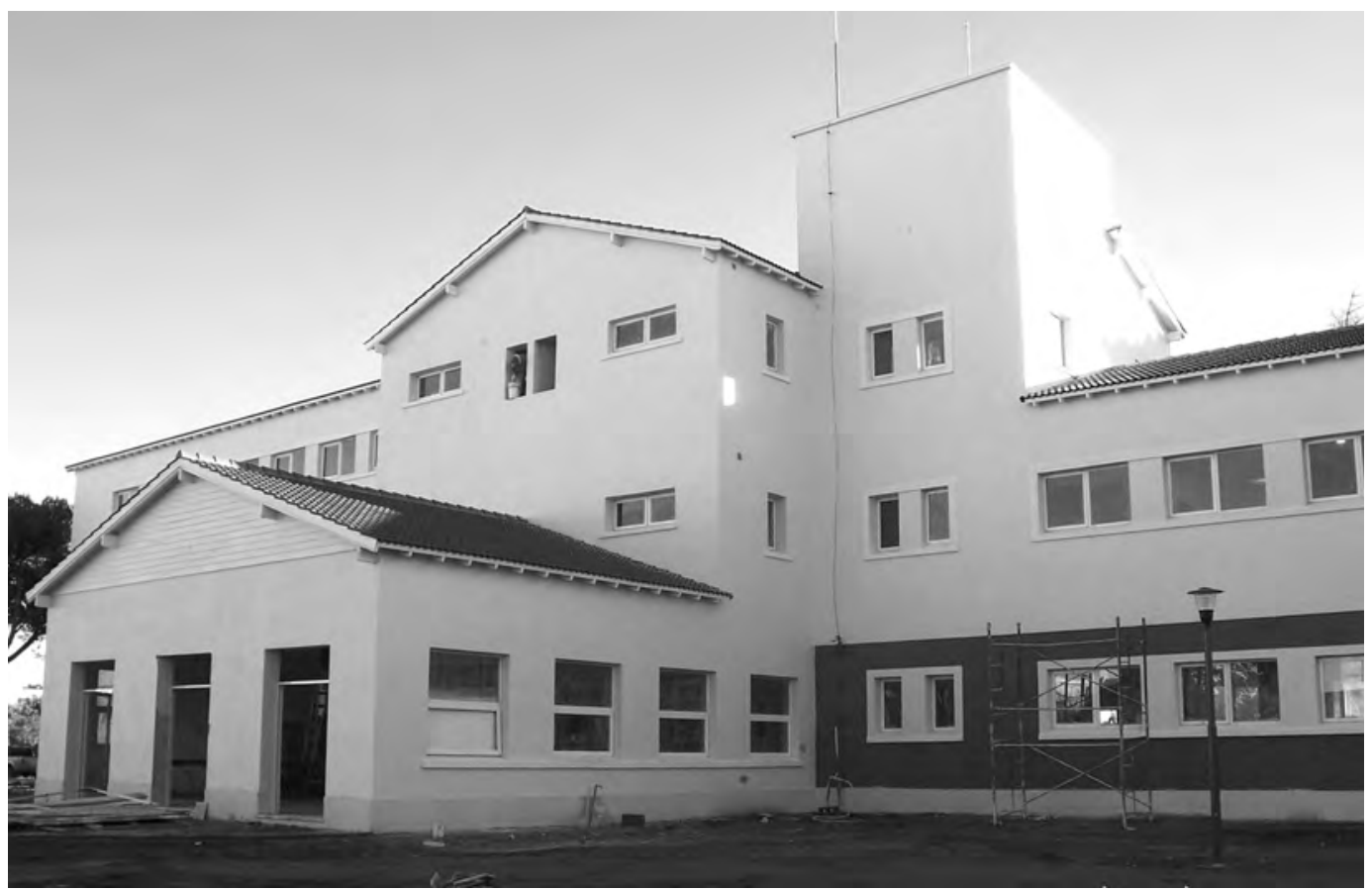

Imagen 10: Frente de la antigua colonia donde hoy funciona la Municipalidad de Monte Hermoso (Foto de la Secretaría de Obras Públicas, Municipalidad de Monte Hermoso)

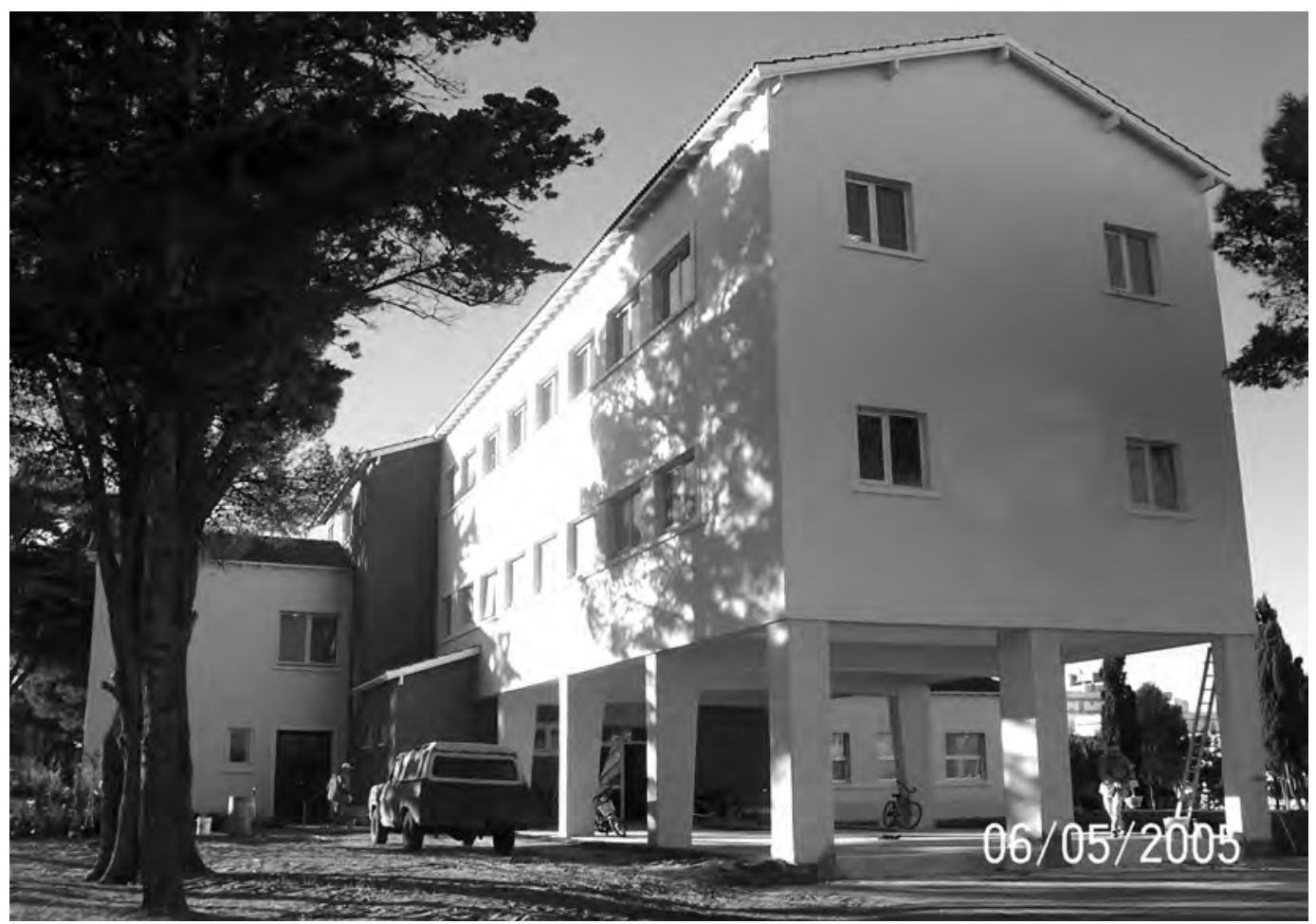

Imagen 11: Vista del acceso debajo del semicubierto (Foto de la Secretaría de Obras Públicas, Municipalidad de Monte Hermoso) 


\section{Consideraciones finales}

El territorio de la provincia de Buenos Aires, con su extensión y variada geografía, hizo posible la localización de los tres tipos de colonias sanitariamente recomendadas para el fortalecimiento de niños débiles: las de llanura, las de sierra y las marítimas, aunque focalizamos aquí en estas últimas. Paralelamente, el llano, el mar y las sierras fueron los puntos de interés tenidos en cuenta para la organización estatal del turismo provincial desde finales de los años 1930.

En el texto se trató de advertir aspectos relevantes de estas experiencias en las colonias escolares que permanecen, o reaparecen, como motivadores del turismo social de las que destaca el estar encaradas por instituciones estatales o religiosas, en favor de los más desprotegidos: los niños primero, los más humildes después, sin desconocer que cada propuesta puede haber respondido a intereses de orden o control social. Es así que se propone el viaje al campo o la playa, lejos de las ciudades y las condiciones de vida perjudiciales para la salud. El efecto reparador del viaje necesita períodos de descanso adecuado. El contacto con la naturaleza y la vida ordenada, la alimentación ajustada, la ejercitación física y los efectos del clima y el mar son también bases de estas propuestas, así como la necesidad de actuar en forma anticipada, fortaleciendo los cuerpos previniendo la enfermedad. La convivencia en estos lugares favorecería, finalmente, la moral y la cultura del individuo, y dispensaría lazos entre los habitantes de las distintas partes del país.

Como se dijo, el debate sobre el valor de las colonias escolares de vacaciones se introduce en el país en el marco del reformismo social. Las primeras experiencias estatales son realizadas desde el campo de la salud en el marco de la lucha antituberculosa y a instancias de políticos del partido radical. Luego, estas experiencias con niños serán utilizadas, ahora en el campo de la educación, por el gobernador Fresco, cristiano, nacionalista y admirador del fascismo italiano. Por último, será en la política de justicia social del peronismo cuando estas acciones se extiendan a la población obrera.

El proyecto de Uspallata toma como referencia para la disposición el hospital higiénico pabellonal. El lugar que concede a las prácticas deportivas, con canchas de tenis, football y stand de tiro no se repetirá en las otras propuestas, en las que solo se necesitaba espacio para juegos y ejercicios, muchos de los cuales se hacen en la playa.

De esa arquitectura hospitalaria perdura la utilización del pabellón, aunque cambia la disposición en los tres casos. En Necochea es el pabellón aislado la base del proyecto: dos "tiras" albergarían quinientos niños, al igual que Mar del Plata. Ambas colonias tenían similar cantidad de metros cubiertos, pero los espacios destinados a actividades comunes comedores y salas de juego - se redujeron a la mitad en la colonia marplatense, por lo que puede suponerse que esas actividades de juego se desplazarían hacia el patio central conformado por pabellones, disposición que les hace perder superficie exterior en detrimento de luz y aireación. En Monte Hermoso el espacio proporcional, destinado a zonas comunes, es como en Mar del Plata, una cuarta parte del edificio, pero el número de camas se reduce casi a la mitad, mientras la superficie total no disminuye en igual proporción, por lo que se dispondría de mayor espacio por ocupante, además de introducir el semi-cubierto de acceso. 
Los pabellones de dormitorios retoman la tira del primer ejemplo, pero se han centralizado los servicios y optimizado el uso del espacio.

Lo que perdura, entonces, deriva de la actividad común de alojar muchos niños en los grandes dormitorios y comedores en pabellones, cuya disposición define la toma de partido. Lo que cambia son escalas y proporciones, complejización de áreas de servicios como resultado de la modernización - cocheras, calderas, espacios semi-cubiertos - y fundamentalmente la expresión estética y formal.

\section{NOTAS}

${ }^{1}$ Escritor, médico y filósofo positivista argentino. Político socialista y hombre de ciencia. Formó parte de los académicos reformistas que no se limitaron al estudio científico de la cuestión social, sino que llevaron sus ideas a la práctica creando o dirigiendo nuevas instituciones; en su caso fue Director del Instituto de Criminología de la Penitenciaría Nacional (Zimmerman, 1992).

${ }^{2}$ La Sociedad Escuelas y Patronatos nació como institución católica, a raíz de la realización en Buenos Aires del Segundo Congreso Terciario Franciscano. Fue fundada por un grupo de damas en el año 1906 y la primera de la República en organizar las colonias de vacaciones para niños débiles, siendo su iniciador y director Fray Julián B. Lagos.

${ }^{3}$ Tosi, al mando de la oficina técnica, realizó también los proyectos del plan de edificación escolar. Técnico especialista - había participado en la construcción de escuelas del centenario en Entre Ríos cuando Antequeda era funcionario en esa provincia, estudió las edificaciones antisísmicas que se realizaban en Italia y Japón, para aplicar estos nuevos modelos de edificación en las escuelas mendocinas.

${ }^{4}$ La contagiosidad del medio en la propagación de la tuberculosis pulmonar era comúnmente aceptada, por lo que la profilaxis comenzaba con el retiro de los recién nacidos de los hogares infectados para la consecuente colocación familiar. A los 2 años, estos niños pasaban al Preventorio Roca, donde continuaban su vida alejada del foco infeccioso, completada con una enseñanza pedagógica, física, moral y práctica. Permanecían allí hasta los 8 años, edad en que ya podían ser entregados a sus padres (Boffi, 1930).

${ }^{5}$ En 1936 y en la colonia de San Antonio de Areco, la que fue destinada a las escuelas Láinez de la provincia de Buenos Aires, se inicia la obra nacional de las colonias del Consejo. Desde 1937 participarían alumnos de las escuelas Láinez de las 14 provincias (Olivieri, 1939). Por ley 4.874 de 1905 - conocida como Láinez - se atribuye potestades al Eestado nacional a crear y dirigir escuelas en las provincias (escuelas Láinez).

${ }^{6}$ Además de su actividad profesional privada (egresó en Buenos Aires en 1913), fue, desde fines de los 1920 , director general de Arquitectura del CNE, y también miembro de la Comisión Nacional de Bellas Artes, y de la Comisión de Estética Edilicia.

${ }^{7}$ Para conmemorar el cincuentenario de la Ley de Educación Común - 1420 de 1884, que establecía la educación primaria obligatoria, gratuita y gradual - el CNE encomendó a la Dirección de Arquitectura un libro - Edificación escolar - que reunía en uno de sus capítulos las concepciones de la repartición.

\section{REFERENCIAS}

ALIATA, Fernando; GENTILE, Eduardo. Hospital. In: Liernur, Jorge; Aliata, Fernando (Dir.). Diccionario de Arquitectura en la Argentina, Estilos, obras, instituciones, ciudades. Buenos Aires: AGEA. p.187-198. 2004.

\section{ÁLVAREZ, Adriana.}

La experiencia de ser un "niño débil y enfermo" lejos de su hogar: el caso del Asilo Marítimo, Mar del Plata, 1893-1920. História, Ciências, SaúdeManguinhos, v.17, n.1, p.13-31. 2010.

ÁLVAREZ, Adriana; REYNOSO, Daniel.

Médicos e instituciones de salud: Mar del Plata 1870-1960. Buenos Aires: Hisa/UNMdP. 1995.
ARGENTINA.

Ministerio de Obras Públicas de la Nación. Labor realizada y en ejecución: breve reseña - diciembre 1942-junio 1947: tres años de labor. Buenos Aires: Kraft. 1947.

BOFFI, Luis L.

Colonias marítimas de niños débiles. Buenos Aires: Imprenta Ferrari Hnos. 1930.

BOYER, Marc.

El turismo en Europa, de la Edad Moderna al Siglo XX. Historia Contemporánea, n.25, p.13-31. 2002 . 
BRUNO, Perla.

Los hoteles de turismo (1930-1955): piezas claves del territorio turístico de la Argentina. Registros: Revista de Investigación Histórica, año 8, n.9, p.54-80. Disponible en: http://faud.mdp.edu.ar/ revistas/index.php/registros/article/view/151. Acceso en: 27 dic. 2012. 2012.

\section{CIUDADES...}

Ciudades argentinas: Mendoza. Ideas y Figuras, año 7, n.127. 16 jul. 1915.

\section{CONCEPTOS...}

Conceptos sobre edificación escolar en la República Argentina. Revista de Arquitectura, año 21, n.170, p.61. feb. 1935.

\section{CUNHA MATOS, Madalena.}

Hotel arquitecture in Portugal. In: Pereira, Manuel Seabra (Ed.). A portrait of the state-of-theart research at the Tecnichal University of Lisbon. Netherland: Springer. p.595-603. 2007.

DESMARÁS, Carlos.

Tiempo libre de los trabajadores: vacaciones y centros de descanso. Buenos Aires: Editorial Jurídica Argentina. 1942.

\section{ESCUELAS...}

Escuelas y patronatos. Asociación Colonias de Niños Débiles y Preventorios Infantiles. Buenos Aires: Imprenta Fabril. 1937.

\section{GEHIN, Marcio.}

Las colonias escolares de vacaciones. $E l$ Monitor de la Educación Común, año 27, n.428, p.504-516. Disponible en: http:// www.bnm.me.gov.ar/ebooks/reader/reader. php?mon=1\&vt=n\&dir=00150825\&num img=504. Acceso en: 10 abr. 2013. 31 mar. 1908 .

HERRERO, María Belén; CARBONETTI, Adrián. La mortalidad por tuberculosis en Argentina a lo largo del siglo XX. História, Ciências, SaúdeManguinhos, v.20, n.2, p.521-536. 2013.

INGENIEROS, José.

Las colonias de vacaciones. El Monitor de la Educación Común, año 27, n.410, p.109-119. Disponible en: http://www. bnm.me.gov.ar/ebooks/reader/reader. php?mon=1\&vt=n\&dir=00150823\&num img=109. Acceso en: 20 dic. 2013. 1907.

JIMÉNEZ MORALES, Eduardo.

La génesis del hotel turístico. In: Pié I Ninet, Ricardo; Rosa Jiménez, Carlos (Ed.). Turismo líquido. Barcelona: Universidad Politécnica de Cataluña. p.1-16. 2013.

LIONETTI, Lucía.

La cuestión social en torno a los niños pobres: las estrategias conjuntas de la escuela pública y las instituciones particulares en la primera mitad del siglo XX. IV Jornadas de Historia Política,
Casa de la Cultura de la Universidad Nacional del Sur, Bahía Blanca. Disponible en: http://www. historiapolitica.com/datos/biblioteca/lionetti_jiv. pdf. Acceso en: 2 feb. 2014. 2009.

MAZZA, Carlos; BRUNO, Perla.

Los hoteles y su equipamiento, arquitectura, ciudad y territorio del turismo. In: Bruno, Perla; Romero, Laura (Coord.). Ciudad balnearia y arquitectura: los hoteles de Mar del Plata en la primera mitad del siglo XX. Mar del Plata: Faud, UNMdP. 2009.

MERCANTE, Domingo.

Mensaje a la Asamblea Legislativa, 3 de mayo de 1949. Senado de la Provincia de Buenos Aires, Diario de Sesiones, $93^{\circ}$ período, 1949. t.1, La Plata Dirección de Impresiones Oficiales, p.7-19. 1950.

MINISTERIO..

Ministerio de Trabajo y Previsión. Tiempo libre y colonias de vacaciones. Buenos Aires: Asesoría de Turismo Social y Vacaciones. 1956.

OLIVIERI, Enrique.

Historia, evolución y organización de las colonias de vacaciones del Consejo Nacional de Educación. El Monitor de la Educación, año 58, n.794, p.54-85. Disponible en: http:// www.bnm.me.gov.ar/ebooks/reader/reader. php?mon=1\&vt=n\&dir=00150929\&num img=54. Acceso en: 21 mar. 2014. 1939.

PASTORIZA, Elisa.

La conquista de las vacaciones: breve historia del turismo en la Argentina. Buenos Aires: Edhasa. 2011.

PASTORIZA, Elisa.

Usted se paga el viaje, la Provincia el hospedaje: Mar del Plata, el turismo social y las vacaciones populares durante el gobierno de Domingo A. Mercante. In: Panella, Claudio (Comp.). El gobierno de Domingo A. Mercante en Buenos Aires (1946-1952): un caso de peronismo provincial. La Plata: ICPBA. p.297-320. 2005.

PEREYRA, Miguel. Educación, salud y filantropía: el origen de las colonias escolares de vacaciones en España. In: História de la Educación, v.1. Salamanca: Ediciones Universidad de Salamanca. p.145-168. Disponible en: hdl.handle.net/10366/79297. Acceso en: 13 jun. 2012. 1982.

PIGLIA, Melina. Autos, rutas y turismo: el automóvil club argentino y el Estado. Buenos Aires: Siglo Veintiuno. 2014.

POUSADA, Rafael.

Economía e historia del turismo español. Historia Contemporánea, n.25, p.203-232. 2002. 
PROVINCIA...

Provincia de Buenos Aires. Cuatro años de Gobierno 1936-1940. Buenos Aires: Kraft. 1940.

RAIMONDI, Alejandro A.

Memoria del Hospital Tornú, Dispensario de Vías Respiratorias, Preventorio Roca y Colonia Marítima de Necochea. Correspondiente al año 1929. Municipalidad de la Ciudad de Buenos Aires. Asistencia Pública. Buenos Aires: Imprenta Mercatali. 1930.

TOSI, Andrés. Memoria descriptiva del proyecto de Colonia Nacional de Vacaciones para niños débiles y maestros desgastados, a construirse en el Valle de Uspallata. In: Dirección General de Escuelas Mendoza. La Colonia de Nacional de Vacaciones para niños débiles y maestros desgastados en el Valle de Uspallata. Buenos Aires: La casa de los maestros. 1915.

ZIMMERMANN, Eduardo.

Los intelectuales, las ciencias y el reformismo liberal: Argentina, 1890-1916. Desarrollo Económico, v.31, n.34, p.545-564. 1992. 